\title{
Laparoscopic surgery in the treatment of gastric phytobezoar
}

\author{
Murat Coşkun,' ๑ Adem Yüksel,, ${ }^{\oplus}$ Murat Burç Yazıcıoğlu’
}

'Department of General Surgery, Kocaeli Health Sciences University Derince Training and Research Hospital, Kocaeli, Turkey

2Department of Gastrointestinal Surgery, Kocaeli Health Sciences University Derince Training and Research Hospital, Kocaeli, Turkey

\begin{abstract}
Gastric phytobezoars are usually treated with conservative (i.e. medical, endoscopic) methods. However, when conservative treatment methods are failed, surgical treatment is inevitable. In this study, we report the results of two gastric phytobezoar cases which were not treated with conservative methods and laparoscopic anterior gastrotomy with four ports was performed. Bezoar was extracted within endobag through the port site after partially enlarging of the incision. Both patients were discharged on the postoperative fifth day. The findings suggest that laparoscopic surgery is a safe and feasible method for the treatment of gastric phytobezoar.
\end{abstract}

Keywords: Bezoar; laparoscopy; phytobezoar.

\section{Introduction}

A bezoar is an indigestible trapped of mass which formed in the gastrointestinal tract by a variety of materials that were intentionally or accidentally ingested. ${ }^{[1]}$ Bezoars are mainly classified into four types according to the material constituting the indigestible mass of the bezoar: phytobezoars, trichobezoars, pharmacobezoars, and lactobezoars. ${ }^{[2]}$ Bezoars can be formed and found in any part of the gastrointestinal tract, but commonly seeing in stomach. ${ }^{[1]}$ In gastric bezoars, the symptoms are usually unclear or nonspecific. Epigastric pain, bloating, early saturation, nausea, vomiting, halitosis and rarely it may cause ulcerative lesion in the stomach and subsequent Bezoarinduced gastric bleeding. ${ }^{[1]}$

The first step of treatment is generally enzymatic dissolution (Coca-Cola $\left.{ }^{\circledR}\right)$, prokinetic drugs and endoscopic methods. However, if these methods failed and/or complications such as bleeding, obstruction and puncture developed, surgical treatment is necessary. ${ }^{[2]}$ The traditional surgical treatment of Bezoar is removed through a laparotomy. ${ }^{[3]}$ In this article, we aimed to discuss two gastric bezoar cases that were successfully removed by laparoscopic approach in which conservative treatment methods have failed.

\section{Case Report}

Case 1 - A 56-year-old male patient was admitted to our outpatient clinic with complaint of epigastric pain and bloating for three months. Physical examination and routine laboratory tests were normal. Abdominal ultrasonography was unremarkable. Upper gastrointestinal system endoscopy revealed about $7 \times 5 \mathrm{~cm}$ size bezoar in the stom- 

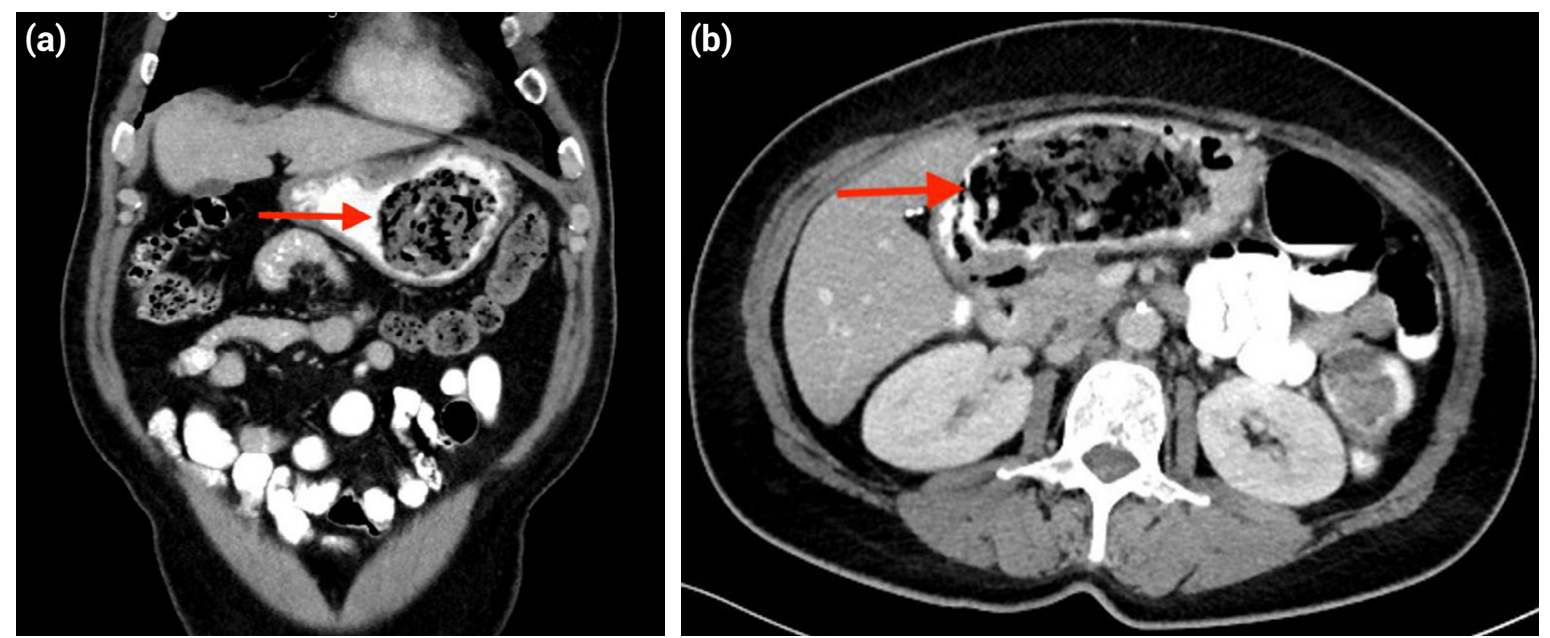

Figure 1. (a, b) CT images of cases 1 and 2 show a non-enhancing intraluminal mixed-intensity intraluminal mass in stomach with foci of air and oral contrast. Mass is limited by oral contrast.

ach, and an ulcus $(1 \times 1 \mathrm{~cm})$ on the level of angular incisure. Histopathological examination of endoscopic biopsy from the edge of ulcer was reported as a benign ulcus. Non-operative endoscopic fragmentation of bezoar was not successful. Coca-Cola ${ }^{\circledR}$, pineapple juice and prokinetic drugs were administered as suggested, ${ }^{[1]}$ but control gastroscopy showed no decrease in the size of the bezoar. Endoscopic fragmentation retired but failed again.

Computed tomography (CT) of the abdomen revealed a $66 \times 45 \mathrm{~mm}$ bezoar in the stomach, with no other synchronous lesions in the gastrointestinal tract (Fig. 1a). Laparoscopic approach was decided.

Case 2 - A 59-year-old female patient was admitted to the outpatient clinic with the complaint of epigastric pain and involuntary weight loss of $15 \mathrm{~kg}$ during the last 3 months. Physical examination and routine laboratory tests were normal. Abdominal ultrasonography was unremarkable. Upper gastrointestinal system endoscopy revealed approximately $14 \times 5 \mathrm{~cm}$ size phytobezoar in the stomach. Coca-Cola $^{\circledR}$ and pineapple juice were administered as suggested. ${ }^{[1]}$ Control gastroscopy showed no decrease in the size of the bezoar. Endoscopic fragmentation retired but failed again. CT revealed that bezoar filled the entire stomach and there was no synchronous lesion in other parts of gastrointestinal system (Fig. 1b). Laparoscopic surgery was applied to the patient.

\section{Surgical Technique}

In both patients, 4 ports ( 2 pieces $10 \mathrm{~mm}, 2$ pieces $5 \mathrm{~mm}$ ) were placed in the abdomen in the supine position (Fig. 2). Using monopolar hook a $5 \mathrm{~cm}$ gastrotomy was made parallel to gastric axis on the anterior wall of gastric body (Fig. 3a). Bezoar was manipulated out of the stomach from this area. In the first case, the endocamera was pushed through the gastrotomy incision and a $1 \mathrm{~cm}$ peptic ulcer was seen at gastric angle (Fig. 3b). After placing the bezoar in laparoscopic endo-bag, the $10 \mathrm{~mm}$ port incision on the left side of abdomen was extended to $4 \mathrm{~cm}$ and after then a wound protector was placed (Alexis ${ }^{\circledR} \mathrm{O}^{\mathrm{TM}} \mathrm{Re}$ tractor. Applied Medical Resources Corporation, Rancho Santa Margarita, CA; USA). The opening of the bag was pulled out through this incision. The bezoar was partially dismantled in the endobag and taken out of the abdomen from this area. In both cases, gastrostomy was closed with continuous prolene $3 / 0$ double layer suture (Fig. 3c). The operations were completed in an average of 80 minutes.

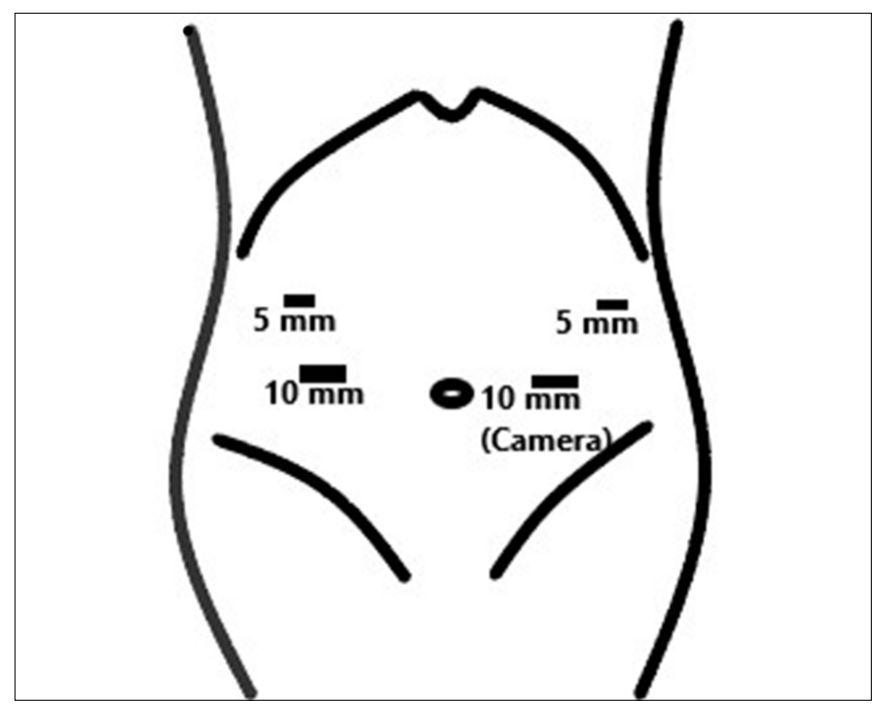

Figure 2. Diagram showing the sites of port placement, and the extension of left lower abdominal wound to $4-\mathrm{cm}$ incision to extract the bezoar piecemeal. 

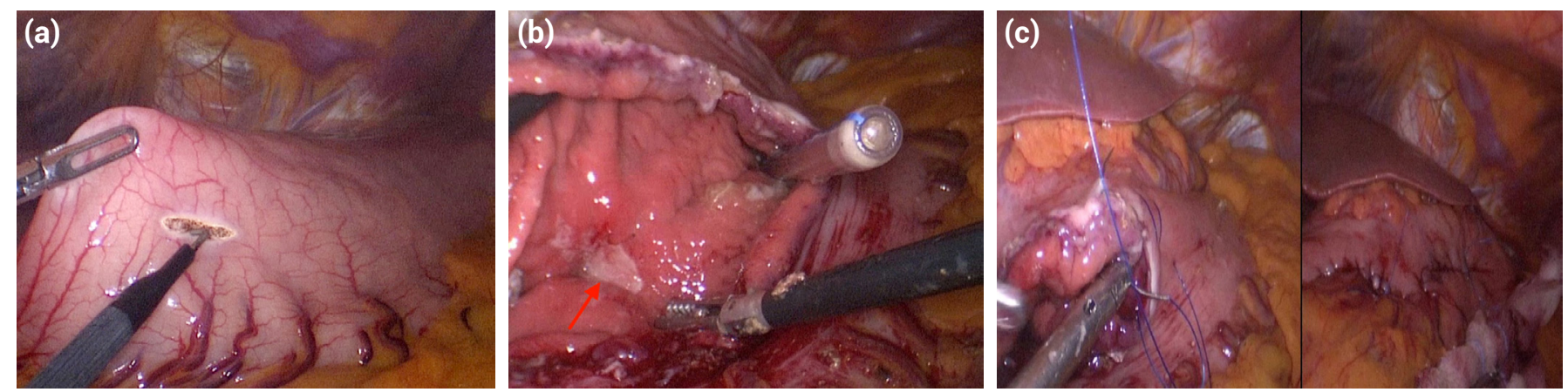

Figure 3. (a) Gastrotomy performed with the help of monopolar cautery parallel to the stomach axis from the proximal of the stomach antrum. (b) Red arrow showing the peptic ulcer observed in the gastric angle in case one. (c) Gastrotomy area was repaired by continuous sutures with $3 / 0$ prolene double layer.

Both patients had no problems in the postoperative period. Oral food was started on the $3^{\text {rd }}$ postoperative day and the patients were discharged on the $5^{\text {th }}$ postoperative day. In the first case, control gastroscopy was performed in the first postoperative month and ulcer site was healed. All patients were previously informed about operation and complications and written informed consent was obtained.

\section{Discussion}

Gastric bezoars are relatively rare and most commonly seen in the mentally retarded, those with bizarre appetite and the emotionally disturbed (trichotillomania; a psychologic disorder in which a person uncontrollably and incessantly pulls out the body hair) or deprived. ${ }^{[3]}$ Phytobezoars are the most common type, and they are mostly located in the stomach. ${ }^{[1]}$ Bezoar formation is common in patients who has chewing disorders and changes in gastrointestinal motility. In addition, over-consumption of some non-digestible composed foods; cellulose, hemicellulose, lignin, and fruit tannins (leucoanthocyanins and catechins), celery, pumpkins, grape skins, prunes, raisins, and most notably persimmons are also important factors in its formation. ${ }^{[1]}$ Previous gastric surgery, peptic ulcer, chronic gastritis, gastrointestinal system diseases, dehydration, diabetes and hypothyroidism are also known risk factors for bezoar development. ${ }^{[4]}$ However, predisposing factors may not be detected in 5.9\% of patients. ${ }^{[5]}$ In our study, mental and physical status of our patients were completely normal and we could not find the risk factor that caused bezoar formation.

Generally, patients present with nonspecific findings such as epigastric pain, nausea, vomiting and weight loss. ${ }^{[2]}$ Endoscopic examinations play an important role in the diagnosis and treatment of gastric bezoars and bezoar is usu- ally seen as a single mass in the gastric fundus in different colours according to the bezoar content. In $22.2 \%$ of the patients, synchronous bezoar was found in the gastrointestinal tract. ${ }^{[4]}$ Therefore, gastrointestinal system should be evaluated by abdominal CT. We evaluated both cases with computed tomography and did not detect a synchronized lesion.

The purpose of bezoar treatment is to remove bezoar or to dissolve it. Medical, endoscopic and surgical methods are used for this purpose. Prokinetic drugs, papain and Coca$\mathrm{Cola}^{\circledR}$ are used in medical treatment. Endoscopic disintegration is also used in treatment. However, the success rate of medical and endoscopic treatments are reported as $89.7 \% .^{[6]}$ Female gender, multiple or large bezoar and tricobezoar have been reported as risk factors for conservative treatment failure. ${ }^{[7]}$ In our two cases, the size of bezoars were the cause of conservative treatment failure. Surgical removal is inevitable in case of failure of conservative treatment or complications such as bleeding, obstruction and puncture. ${ }^{[2]}$

Today, laparoscopic surgery has replaced conventional surgery in many gastrointestinal procedures. However, there have been a few reports on laparoscopic approach for the treatment of gastric bezoar but unfortunately all of them are case reports. ${ }^{[3,8-10]}$ There are some criticisms about laparoscopic surgery that it prolongs the operation time. ${ }^{[3]}$ The main factors about prolongation of operation time are the techniques chosen for removal of the bezoar and closure of gastrotomy. ${ }^{[9]}$ Different techniques have been described both for the removal of bezoar and to minimize the risk of contamination of the intraabdominal bezoar. Bezoar is usually placed in a laparoscopic endo-bag after or without disintegration in the stomach, and then removed from the extended port incision or suprapubic incision. ${ }^{[8-10]}$ This disintegration also takes a lot of time 
and can a prolong the operation time. Therefore, the bezoars were placed in the endobag without disintegration in two cases and were completed in 80 minutes.

The second criticism is that the cost of staplers used to close the gastrotomy increases the cost of operation. ${ }^{[9,11]}$ Though case reports are not suitable for compare the costeffectivity, we believe that gastrotomy can be closed with intracorporal sutures without prolonging the operation time, as in experienced centers. Thus, the increase in operating costs is prevented. In addition, the advantages of laparoscopic surgery such as shorter hospital stay, early return to work and better cosmetic results should be considered in the cost-effectivity.

In conclusion, laparoscopic surgery is an effective, safe and applicable technique for the treatment of gastric phytobezoars which cannot be treated by conservative methods.

\section{Disclosures}

Informed Consent: Written informed consent was obtained from the patient for the publication of the case report and the accompanying images.

Peer-review: Externally peer-reviewed.

Conflict of Interest: None declared.

\section{References}

1. Sanders MK. Bezoars: from mystical charms to medical and nutritional management. Pract Gastroenterol
2004; 18:37-50.

2. Iwamuro $M$, Okada $H$, Matsueda $K$, Inaba $T$, Kusumoto $C$, Imagawa $\mathrm{A}$, et al. Review of the diagnosis and management of gastrointestinal bezoars. World J Gastrointest Endosc 2015;7:336-45. [CrossRef]

3. Shami SB, Jararaa AA, Hamade A, Ammori BJ. Laparoscopic removal of a huge gastric trichobezoar in a patient with trichotillomania. Surg Laparosc Endosc Percutan Tech 2007;17:197-200. [CrossRef]

4. Kement M, Ozlem N, Colak E, Kesmer S, Gezen C, Vural S. Synergistic effect of multiple predisposing risk factors on the development of bezoars. World J Gastroenterol 2012;18:960-4.

5. Erzurumlu K, Malazgirt Z, Bektas A, Dervisoglu A, Polat C, Senyurek $G$, et al. Gastrointestinal bezoars: a retrospective analysis of 34 cases. World J Gastroenterol 2005;1 1:1813-7.

6. Park SE, Ahn JY, Jung HY, Na S, Park SJ, Lim H, et al. Clinical outcomes associated with treatment modalities for gastrointestinal bezoars. Gut Liver 2014;8:400-7. [CrossRef]

7. Mihai C, Mihai B, Drug V, Cijevschi Prelipcean C. Gastric bezoars-diagnostic and therapeutic challenges. J Gastrointestin Liver Dis 2013;22:111.

8. Song $\mathrm{KY}$, Choi BJ, Kim SN, Park $\mathrm{CH}$. Laparoscopic removal of gastric bezoar. Surg Laparosc Endosc Percutan Tech 2007;17:42-4. [CrossRef]

9. Sharma D, Srivastava M, Babu R, Anand R, Rohtagi A, Thomas S. Laparoscopic treatment of gastric bezoar. JSLS 2010;14:263-7. [CrossRef]

10. Ulukent SC, Ozgun YM, Şahbaz NA. A modified technique for the laparoscopic management of large gastric bezoars. Saudi Med J 2016;37:1022-4. [CrossRef]

11. Nirasawa $\mathrm{Y}$, Mori T, Ito $\mathrm{Y}$, Tanaka H, Seki N, Atomi Y. Laparoscopic removal of a large gastric trichobezoar. J Pediatr Surg 1998;33:663-5. [CrossRef] 